\title{
Complete rupture of the flexor hallucis longus tendon in an isolated closed injury. A systematic literature and qualitative analysis
}

\author{
D.L. Kerr ${ }^{1}$, S. Butler², K. Thompson ${ }^{1}$, A. Higgs ${ }^{1,3}$ \\ 1 St Vincent's Hospital, Sydney, Australia \\ 2 Sydney Hand and Eye Hospital, Sydney, Australia \\ 3 University of Notre Dame, Sydney, Australia
}

CORRESPONDING AUTHOR:

David L. Kerr

St Vincent's Hospital

E-mail: Davidkerr56@gmail.com

Phone: 0400242801

DOI:

10.32098/mltj.01.2019.09

\begin{abstract}
SUMMARY
Background. Complete rupture of the flexor hallucis longus tendon in an isolated closed injury is a rare event. The infrequent identification of this injury may be due to a low clinical suspicion of the flexor hallucis longus tendon being a source of pathology in closed foot and ankle injuries. This review will assess the current body of literature and analyse the clinical presentation and current concepts in management of this specific pattern of tendon injury. Method. A systematic literature search was conducted in MEDLINE and Embase to identify relevant publications. Two separate researchers independently reviewed the references identified in the literature search, with each article being assessed against published selection criteria specified in the study protocol registered with PROSPERO. Two reviewers individually examined the raw data presented in each paper that met final inclusion criteria. This data was then presented in the final analysis. Results. There were 10 documented case reports of complete rupture of the flexor hallucis longus tendon in an isolated closed injury reported in the literature. The majority of subjects were male $(70 \%)$, with an average age of 38 years. The duration of prodromal symptoms ranged from 0-8 months. The most common mechanism of injury was running, seen in $30 \%$ of cases. Every documented case in the literature underwent surgical management. Common post-operative outcomes reported were individual joint range of motion and return to prior level of physical activity. Conclusion. Due to the occult nature of the injury and synergistic function of other structures in the foot, delayed presentation of closed flexor hallucis tendon rupture is common. It is unclear from the current body of literature if surgical management of this injury significantly improves patient outcomes. Current evidence from the management of open flexor hallucis longus tendon ruptures suggests that patients can achieve good functional outcomes with non-operative management. Our recommendation would be for initial non-operative treatment of closed flexor hallucis longus tendon ruptures given the potential for acceptable functional outcomes, and to avoid the potential complications associated with operative repair.
\end{abstract}

\section{KEY WORDS}

flexor hallucis longus; FHL; closed injury; complete rupture; tendon rupture non-operative

\section{INTRODUCTION}

Complete rupture of the flexor hallucis longus tendon in an isolated closed injury is a rare even (5). The infrequent identification of this injury may be due to a low clinical suspicion of the flexor hallucis longus tendon being a source of pathology in closed foot and ankle injuries (5).
This paper will present a systematic review of all documented case reports describing isolated complete flexor hallucis longus tendon ruptures in closed injuries. This review will assess the current body of literature and analyse the clinical presentation and current concepts in management of this specific pattern of tendon injury. 


\section{BACKGROUND}

Complete rupture of the flexor hallucis longus tendon as an isolated closed injury is an extremely rare event $(1,5)$. Whilst there have been two review articles published in this area, the reported incidence of this specific injury ranges significantly between publications $(5,10)$.

In an initial literature review published by Grispigni et al. in 2000, they reported eight cases of complete flexor hallucis longus tendon rupture in a closed injury (5). In a subsequent review article published by Noda et al. 2012, the authors reported there are as many as thirty-five published case reports in the literature (10). Whilst these reviews articles add to the overall knowledge of this rare injury pattern, there is significant variation in research methodology and inclusion criteria between the two articles.

It is the aim of this review to present the outcomes of complete rupture of the flexor hallucis longus tendon in isolated closed injuries following both operative and non-operative management. This publication hopes to better elucidate the patient demographics and clinical presentation associated with this type of injury, through combined analysis of all published data. In addition to a systematic literature review, this paper will present a further case report an isolated complete rupture of a flexor hallucis longus tendon following a closed hyperdorsiflexion injury.

\section{METHODS}

\section{Research protocol registration}

Research protocol registration was obtained through PROSPERO and can be found at the following web address: http://www.crd.york.ac.uk/PROSPERO/display_record. php?ID=CRD42018096098.

Trial registration number CRD42018096098.

\section{Search strategy}

A literature search using key terms and medical subject headings (MeSH) was conducted in MEDLINE and Embase to identify relevant publications. Publications were limited to English language with no restriction to year of publication. All articles identified from the literature search were assessed against inclusion criteria as detailed bellow. Two independent reviewers assessed every reference against predetermined inclusion and exclusion published at PROSPERO prior to commencing the review. The reference lists of included publications were further screened for relevant publications. (appendix 1).

\section{Inclusion criteria}

This review included any publication reporting on patients who have experienced an isolated closed flexor hallucis longus tendon rupture. Flexor hallucis longus tendon rupture was defined as a complete rupture with $100 \%$ loss of tendon continuity. Diagnosis may be clinical, radiographic or under direct vision intraoperatively. Tendon ruptures resulting from percutaneous injuries or open laceration were excluded. Partial tendon ruptures were not included.

\section{Exclusion criteria}

Tendon rupture as a result of laceration; tendon rupture as a result of percutaneous injuries; partial flexor hallucis longus tendon rupture; flexor hallucis longus rupture in association with other injuries.

\section{Studies included}

Eighty-three articles were retrieved in the initial search strategy (appendix 1). Following the removal of duplicate articles, 68 of these articles were evaluated to determine relevance to the systematic review. Fifty-one of these articles

\section{Appendix 1}

Database: Embase <1996 to 2018 May 01>

Search Strategy:

1 flexor hallucis longus.mp. (704)

2 flexor hallucis longus.mp. (9)

31 or 2 (712)

4 achilles tendon rupture/ (1908)

5 tendon rupture/ (3296)

6 rupture.mp. or rupture/ (118232)

75 or 6 (118232)

87 not $4(116324)$

93 and 8 (64)

10 limit 9 to english language (57)

\section{Database: Ovid MEDLINE(R) $<1996$ to Present with Daily Update>}

Search Strategy:

1 flexor hallucis longus.mp. (5)

2 flexor hallucis longus.mp. (469)

3 exp Achilles Tendon/ (4757)

41 or $2(473)$

54 not 3 (370)

6 RUPTURE/ or rupture.mp. (62970)

75 and 6 (26)

8 limit 7 to english language (25) 
were excluded from the review due to failure to meet selection criteria outline in the research protocol. The final ten studies included for review were published between 1990 and 2012.

\section{Data collection process}

Two reviewers individually examined the raw data presented in each paper that met final inclusion criteria. Results were compared between reviewers with any discrepancies referred to a third reviewer. This data was then used in the final analysis.

\section{Data items}

The principal data item of this review was the clinical and functional outcomes following both operative and non-operative management of complete rupture of the flexor hallucis longus tendon in isolated closed injuries. A secondary objective of this systematic review was to better elucidate the patient demographics and clinical presentation associated with this type of injury through combined analysis of all published data.

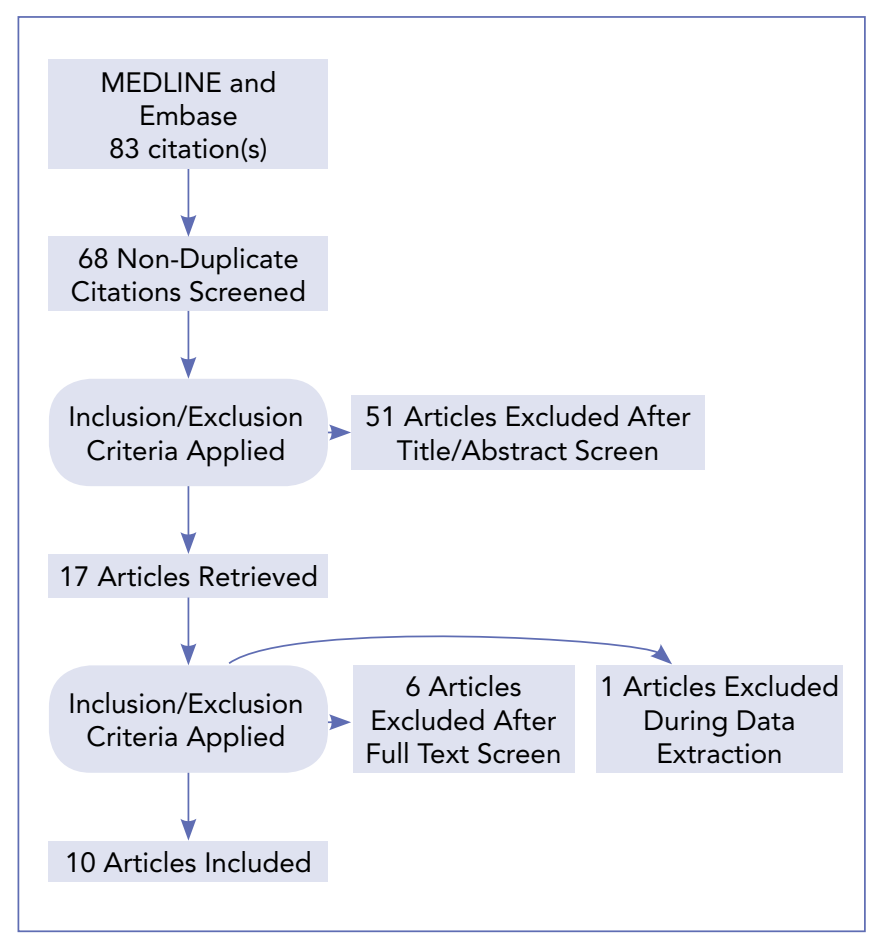

Figure 1 - Flow diagram of systematic search and review of citations.

\section{RESULTS}

Following a systematic literature search, ten papers reported complete rupture of the flexor hallucis longus tendon as an isolated closed injury. The majority of subjects were male $(70 \%)$, with an average age of 38 years. The duration of prodromal symptoms ranged from 0-8 months, and only one of the reported cases had a prior history of local or systemic factors that may have contributed to the rupture. The physical demands of the subjects ranged from elite athletes through to a nonathletic population. The most common mechanism of injury was running, seen in 30\% of cases.

The diagnosis was often made clinically and confirmated by MRI and open surgical exposure. Anatomical locations of tendon rupture were noted to be the head of the first metatarsal, the mid foot and posterior to the medial malleolus, respectively. Every case documented in the literature underwent surgical management, with a number of surgical techniques utilised. A key factor in surgical repair was the ability to approximate the tendon ends, predominantly affected by the location and chronicity of the tendon rupture.

\section{CASE REPORT}

A 60 year-old male presented with a 2-month history of medial hindfoot pain and an inability to flex his right hallux, following an injury sustained whilst at work as a store man. He reported a forced dorsiflexion type injury to his right foot and ankle while stepping backwards off of a small step. He experienced medial hindfoot pain which remained constant until ten days post initial injury, when he felt a sudden snapping sensation behind the ankle. After presentation to his GP and a trial of conservative management, an MRI was obtained that showed an isolated complete rupture of the flexor hallucis longus tendon.

Due to extenuating personal circumstances, the patient did not present for orthopaedic opinion until two months following initial injury. His primary complaints at the time of presentation were an inability to flex his interphalangeal joint, and mild to moderate medial hindfoot and ankle pain. He was otherwise well at the time of injury and no risk factors for tendon rupture were identified on history. His medical history included gastroesophageal reflux disease, hypertension, hypercholesterolaemia and hyperthyroidism. He denied any recent change in physical activity prior to the injury and did not participate in any regular physical activity. On clinical examination, he had a physiological body habitus with neutral lower limb alignment. No cock-up deformity of the great toe was noted. There was no evidence of 
Table I - Patient characteristics. Table of results: patient demographics $(1,5-8,10-14)$.

\begin{tabular}{|c|c|c|c|c|c|c|c|c|}
\hline Author & Demographics & \begin{tabular}{|l|} 
Medical \\
comorbidities
\end{tabular} & $\begin{array}{l}\text { Duration of } \\
\text { symptoms }\end{array}$ & Physical demands & Mechanism of injury & Diagnosis & $\begin{array}{l}\text { Location of } \\
\text { rupture }\end{array}$ & Classification \\
\hline Holt 1990 & $\begin{array}{l}42 \text { year old } \\
\text { female }\end{array}$ & $\begin{array}{l}\text { No hx of systemic } \\
\text { illness OR local } \\
\text { injections }\end{array}$ & 2 months & Marathon runner & Running & $\begin{array}{l}\text { Clinical and } \\
\text { confirmed } \\
\text { surgically }\end{array}$ & Mid foot & Repetitive strain \\
\hline \begin{tabular}{|l|} 
Van \\
Jonbergen \\
2001 \\
\end{tabular} & $\begin{array}{l}52 \text { year old } \\
\text { male }\end{array}$ & $\begin{array}{l}\text { No hx of systemic } \\
\text { illness OR local } \\
\text { injections }\end{array}$ & 6 months & $\begin{array}{l}\text { No regular physical } \\
\text { activity }\end{array}$ & $\begin{array}{l}\text { Impingment of an os } \\
\text { trigonum }\end{array}$ & $\begin{array}{l}\text { MRI and } \\
\text { confirmed } \\
\text { surgically }\end{array}$ & $\begin{array}{l}\text { Posterior to } \\
\text { medial } \\
\text { malleolus }\end{array}$ & Non-traumatic \\
\hline Wei 1998 & $\begin{array}{l}31 \text { year old } \\
\text { male }\end{array}$ & $\begin{array}{l}\text { No hx of systemic } \\
\text { illness OR local } \\
\text { injections }\end{array}$ & 1 year & $\begin{array}{l}\text { No regular physical } \\
\text { activity }\end{array}$ & Insidious & $\begin{array}{l}\text { MRI and } \\
\text { confirmed } \\
\text { surgically }\end{array}$ & Mid foot & Non-traumatic \\
\hline \begin{tabular}{l|} 
Thompson \\
1993
\end{tabular} & $\begin{array}{l}53 \text { year old } \\
\text { female }\end{array}$ & $\begin{array}{l}\text { Background history of } \\
\text { rheumatoid arthritis }\end{array}$ & 2 weeks & $\begin{array}{l}\text { Regular walking } \\
\text { and water aerobics }\end{array}$ & Walking & $\begin{array}{l}\text { MRI and } \\
\text { confirmed } \\
\text { surgically }\end{array}$ & hindfoot & Repetitive strain \\
\hline $\begin{array}{l}\text { Coghlan } \\
1993\end{array}$ & $\begin{array}{l}48 \text { year old } \\
\text { male }\end{array}$ & $\begin{array}{l}\text { No hx of systemic } \\
\text { illness OR local } \\
\text { injections }\end{array}$ & 4 months & Runner & Running & $\begin{array}{l}\text { Clinical and } \\
\text { confirmed } \\
\text { surgically }\end{array}$ & Mid Foot & Repetitive strain \\
\hline $\begin{array}{l}\text { Grispigni } \\
2000\end{array}$ & $\begin{array}{l}27 \text { year old } \\
\text { male }\end{array}$ & $\begin{array}{l}\text { No hx of systemic } \\
\text { illness OR local } \\
\text { injections }\end{array}$ & 8 months & $\begin{array}{l}\text { Runner and } \\
\text { amateur football } \\
\text { player }\end{array}$ & Insidious & $\begin{array}{l}\text { ultrasound, MRI } \\
\text { and confirmed } \\
\text { surgically }\end{array}$ & Head of 1st MT & Repetitive strain \\
\hline \begin{tabular}{l|} 
Rasmussen \\
1990
\end{tabular} & $\begin{array}{l}34 \text { year old } \\
\text { male }\end{array}$ & $\begin{array}{l}\text { No hx of systemic } \\
\text { illness OR local } \\
\text { injections }\end{array}$ & NA & Not specified & $\begin{array}{l}\text { Twisting injury to right } \\
\text { foot }\end{array}$ & $\begin{array}{l}\text { Clinical and } \\
\text { confirmed } \\
\text { surgically }\end{array}$ & Head of 1st MT & Acute trauma \\
\hline $\begin{array}{l}\text { Romash19 } \\
94\end{array}$ & $\begin{array}{l}40 \text { year old } \\
\text { male }\end{array}$ & $\begin{array}{l}\text { No hx of systemic } \\
\text { illness OR local } \\
\text { injections }\end{array}$ & 2-3 weeks & Marathon runner & Running & $\begin{array}{l}\text { MRI and } \\
\text { confirmed } \\
\text { surgically }\end{array}$ & Head of 1st MT & Repetitive strain \\
\hline $\begin{array}{l}\text { Inokuchi } \\
1997\end{array}$ & $\begin{array}{l}27 \text { year old } \\
\text { male }\end{array}$ & $\begin{array}{l}\text { No hx of systemic } \\
\text { illness OR local } \\
\text { injections }\end{array}$ & 1 month & Soccer & $\begin{array}{l}\text { Local factors relating } \\
\text { to a previous fracture } \\
\text { of the posterolateral } \\
\text { tubercle of the talus }\end{array}$ & $\begin{array}{l}\text { MRI and } \\
\text { confirmed } \\
\text { surgically }\end{array}$ & $\begin{array}{l}\text { Posterior } \\
\text { process of talus }\end{array}$ & Repetitive strain \\
\hline Noda 2012 & $\begin{array}{l}27 \text { year old } \\
\text { female }\end{array}$ & $\begin{array}{l}\text { No hx of systemic } \\
\text { illness OR local } \\
\text { injections }\end{array}$ & 1 month & NA & $\begin{array}{l}\text { Forced dorsiflexion } \\
\text { type injury }\end{array}$ & $\begin{array}{l}\text { MRI and } \\
\text { confirmed } \\
\text { surgically }\end{array}$ & Head of 1st MT & Traumatic \\
\hline
\end{tabular}

skin laceration or open wounds identified and he was able to walk with equal weight bearing and normal stride length. He was able to perform a unilateral calf raise and demonstrated full passive range of motion at the metatarsophalangeal and interphalangeal joints. He was able to achieve full active extension of the digit compared to the contralateral side; however, he was unable to achieve active flexion of the toe at the interphalangeal and metatarsophalangeal joint.

An X-ray of the right foot demonstrated physiological alignment and no evidence of fracture. An incidental finding of a small os trigonum was noted on the lateral projection. MRI revealed a full thickness rupture of the flexor hallucis longus tendon. The proximal margin was retracted $16 \mathrm{~mm}$ superior, to the level of the tibiotalar joint.

Two months following the initial injury a Foot and Ankle Ability Measure (FAAM) was completed. Moderate impairment was noted with walking up hills, squatting as well as heavy pushing / pulling activities. He rated his current level of function at $90 \%$ when compared to his premorbid level of function.
Following ongoing clinical review and observation, a decision was made to continue non-operative management due to the low level of functional impairment. A key determinant in this decision was the chronicity of the injury and delayed presentation.

\section{DISCUSSION}

Clinical identification of complete closed ruptures of the flexor hallucis longus tendon remains a difficult diagnosis. A consistent feature of all case reports published in the literature is a significant delay from the time of injury to presentation and subsequent diagnosis.

The primary actions of the muscle include plantarflexion of the ankle, maintenance of the longitudinal arch, as well as flexing every joint of the hallux (9). Functionally, a key demand of the muscle is seen in the push off phase of gait, where it is responsible for forward propulsion and locomotion of the centre of mass $(4,9)$. However, the fact that there is such a delay to presentation also highlights the effective 
compensation of the surrounding active and passive structures with synergistic function (12). Pain was often the principal presenting symptom in many of the cases obtained in our review, suggesting that significant functional impairment is not often encountered in this presentation.

Given the ability of the synergistic structures to partially compensate for the function of the flexor hallucis longus muscle, it is surprising to see that every case published in the literature was treated with surgical repair despite presentation as late as fifty-eight days post initial injury (10) (table II). Operative repair has traditionally been achieved with a variety of surgical methods. With a delayed presentation and subsequent tendon retraction, tenodesis to adjacent muscles such as the flexor digitorum longus and flexor hallucis brevis has been utilised $(5,13,14)$. Aside from end to end repair, autograft using iliotibial band has also been used (7). Post-operatively outcomes generally measured were the range of motion of the first metatarsophalangeal and interphalangeal joints, pain and return to previous level of activity. A significant drawback in all of the published case reports is a lack of clinical and functional outcome measures or standardised scoring systems. Whilst this specific injury is extremely rare, there is a complete lack of published case reports of outcomes following the non-operative management of this injury.

Whilst pain, restoration of function and prevention of a cock-up deformity are the main indications given for surgical intervention, the natural history of these injuries is not well known. The time period for resolution of pain after the acute rupture following prolonged prodromal pain is not known. Pain, as an indication for surgery is a debatable notion, given pain may resolve post-operatively due to its natural history alone. Restoration of function in terms of interphalangeal joint range of motion is rarely acquired, as seen from the documented case reports (table II). This is likely due to adhesions from post-operative immobilisation. The healing response of an untreated rupture is likely to result in a similar scarring and tenodesis effect, albeit possibly not in the anatomical position. Active protocols to prevent adhesions of repaired tendons such as those in the hand are not practical in the foot.

Cock-up deformity of the metatarsophalangeal joint following closed complete flexor hallucis longus tendon rupture has not been reported in the literature, unlike a cock-up of

Table II - Operative management and patient outcomes (1,5-8,10-14).

\begin{tabular}{|c|c|c|c|}
\hline Author & Management & $\begin{array}{l}\text { Time of } \\
\text { injury }\end{array}$ & Reportinging of post operative outcomes \\
\hline Holt 1990 & $\begin{array}{l}\text { Operative repair with } \\
\text { Immobilisation for } 8 \text { weeks } \\
\text { followed by graduated return to } \\
\text { activities }\end{array}$ & 3 days & $\begin{array}{l}\text { Approximately } 8 \text { weeks after removal of the cast, the pateint began jogging again. Toe function was good, painless, and showed a } 70 \% \\
\text { range of movement at the metatarsophalangeal joint in comparison to the other side, with equal restriction at both extremes. }\end{array}$ \\
\hline $\begin{array}{l}\text { Van } \\
\text { Jonbergen } \\
2001\end{array}$ & $\begin{array}{l}\text { Operative repair with } \\
\text { Immobilisation for } 4 \text { weeks } \\
\text { followed by graduated return to } \\
\text { activities }\end{array}$ & $\begin{array}{l}2 \\
\text { month }\end{array}$ & $\begin{array}{l}\text { Ten months after the procedure the patient had no pain with good sensibility in the foot. There was normal alignment in the first MTP and } \\
\text { IP joints. Active flexion in the MTP-I joint was complete, active IP flexion however, was not possible }\end{array}$ \\
\hline Wei 1998 & $\begin{array}{l}\text { Operative debridment and } \\
\text { tenodesis of FHL to FDL followed } \\
\text { by graduated return to activities }\end{array}$ & NA & $\begin{array}{l}\text { The patient is doing well postoperatively. He has only mild, intermittent pain in the medial midfoot } 1 \text { year after surgery. He has returned to } \\
\text { work without restrictions and is able to perform all job requirements without difficulty. Flexion strength of the left hallux IP joint is now } \\
50 \% \text { versus the contralateral side. }\end{array}$ \\
\hline \begin{tabular}{|l|l|l} 
Thompson19 \\
93
\end{tabular} & $\begin{array}{l}\text { Operative debridment and } \\
\text { tenodesis of FHL to FDL followed } \\
\text { by graduated return to activities }\end{array}$ & NA & $\begin{array}{l}\text { At } 6 \text { months followup, the patient was satisfied. Her toe no longer hit the top of her toe box as it had preoperatively. With the toe held in } \\
\text { dorsiflexion, she had } 35^{\prime \prime} \text { of active flexion at the IP joint. With the metatarsophalangeal joint flexed the IP joint had a few degrees of plantar } \\
\text { flexion, but less than the unaffected side. She had equal dorsiflexion in both IP joints. She had resumed her walking to and from work for } \\
\text { exercise. }\end{array}$ \\
\hline \begin{tabular}{|l|l|l|l} 
Coghlan \\
1993
\end{tabular} & $\begin{array}{l}\text { Operative repair followed by } 3 \\
\text { weeks of plaster immobilisation } \\
\text { and a further } 6 \text { weeks in a dynamic } \\
\text { splint before graduated return to }\end{array}$ & NA & $\begin{array}{l}\text { At } 12 \text { weeks postoperatively the patient started gentle jogging, but it was noted that a } 10^{\circ} \text { of flexion deformity of the hallux interphalangeal } \\
\text { joint persisted. Adequate pushoff had not been restored and disabling hallux pain and subungual hematoma formation occurred following } \\
\text { his training. At outpatient review at } 6 \text { months postoperatively, the patient was running } 25 \text { miles a week without pain or disability. The } \\
\text { hallux toenail was growing normally, and the callositypatternon thesolewas normal. }\end{array}$ \\
\hline $\begin{array}{l}\text { Grispigni } \\
2000\end{array}$ & $\begin{array}{l}\text { Operative debridment and } \\
\text { tenodesis of FHL to FHB followed } \\
\text { by } 4 \text { weeks of immobilisation and } \\
\text { graduated return to activities }\end{array}$ & months & $\begin{array}{l}\text { Eight months after surgery the patient is walking without pain and is back at his usual work. He occasionally practices football and when } \\
\text { running does not complain of any problems involving balance or thrust. His big toe is normally positioned and his distal phalanx is not } \\
\text { hyperextended. Although there is no active plantar flexion of the distal phalanx, there is modest overall plantar flexion of the toe. }\end{array}$ \\
\hline \begin{tabular}{|l|} 
Rasmussen \\
1990
\end{tabular} & $\begin{array}{l}\text { Operative repair with } \\
\text { Immobilisation for } 6 \text { weeks } \\
\text { followed by graduated return to }\end{array}$ & \begin{tabular}{l|l} 
Not \\
specifie \\
d
\end{tabular} & $\begin{array}{l}\text { On examination } 13 \text { months postoperatively there was only minimum active flexion of the interphalangealjoint but no limitations in passive } \\
\text { movement. He felt no inconvenienceand has returned to his work as a carpenter without problems. }\end{array}$ \\
\hline \begin{tabular}{|l|} 
Romash1994 \\
\end{tabular} & $\begin{array}{l}\text { Operative repair with } \\
\text { Immobilisation for } 4 \text { weeks } \\
\text { followed by graduated return to } \\
\text { activities }\end{array}$ & $\begin{array}{l}\text { Not } \\
\text { specifie } \\
\text { d }\end{array}$ & $\begin{array}{l}\text { At } 20 \text { months, the patient had resumed his running at previous distances. He reported that the subjective loss of pushoff noted with the } \\
\text { injury had been corrected. There was no flexion at the interphalangeal joint. The interphalangealjoint had maintained passive } \\
\text { plantarflexion. The metatarsophalangealjoint had retained unrestricted range of motion, i.e., there was no loss of dorsiflexion at this joint. } \\
\text { A postoperative MRI demonstrated scarring in the area of the repair, with continuity of the tendon restored. }\end{array}$ \\
\hline $\begin{array}{l}\text { Inokuchi } \\
1997\end{array}$ & $\begin{array}{l}\text { Operative repair with } \\
\text { Immobilisation for } 4 \text { weeks } \\
\text { followed by graduated return to }\end{array}$ & month & $\begin{array}{l}\text { Two years after the operation, the active range of motion of the IP joint of the right great toe was } 10^{\circ} \text { to } 50^{\circ} \text { (the left toe, } 0^{\circ} \text { to } 60^{\circ} \text { ). The } \\
\text { pain and tenderness of the posteromedial portion of the ankle joint resolved, and the patient was participating in soccer } 2 \text { days a week. }\end{array}$ \\
\hline Noda 2012 & $\begin{array}{l}\text { Operative repair with } \\
\text { Immobilisation for } 6 \text { weeks } \\
\text { followed by graduated return to }\end{array}$ & 58 days & $\begin{array}{l}\text { On examination, } 7 \text { months postoperatively, } 15 \text { active flexion of the IP joint was present, and the power of flexion of the great toe was } \\
\text { almost equivalent to that of the unaffected side. She experienced no inconvenience with any activity. }\end{array}$ \\
\hline
\end{tabular}


the interphalangeal joint (9). A cock-up deformity of the metatarsophalangeal joint has traditionally occurred from intrinsic weakness (Charcot-Marie-Tooth) or absence (flexor hallucis brevis insertion resection after a Keller resection). The hyperextension of the metatarsophalangeal joint from extensor hallucis longus should not occur in isolated flexor hallucis longus ruptures, as long as flexor hallucis brevis is still intact to resist this deformity.

Finally, interphalangeal hyperextension was reported as the indication for one case (9). Passive ability to hyperextend the interphalangeal joint may predispose to this; however, attenuation of the plantar plate would have to occur to create this deformity in a patient without passive hyperextension. Should an interphalangeal hyperextension deformity occur, it could be treated with delayed flexor hallucis longus tenodesis or an interphalangeal joint arthrodesis.

Regarding flexion deformity, one operatively treated case was revised due to overtensioning and persistent interphalangeal joint flexion post-operatively, treated with a $\mathrm{Z}$ lengthening.

Two studies of open lacerated flexor hallucis longus injuries have reported on non-operatively treated patients. Five of 23 injuries were treated non-operatively when combining the data of the two papers, with 3 having no reported residual functional deficits, 1 reporting occasional tripping over the great toe and 1 undergoing delayed surgery for metatarsophalangeal hyperextension $(2,3)$. These studies highlight the ability to successfully treat these injuries non-operatively, and also for delayed surgical intervention to be as efficacious as acute surgery.

\section{CONCLUSION}

Complete rupture of the flexor hallucis longus tendon after a seemingly innocuous event or closed injury is often overlooked in foot and ankle pathology. Due to the occult nature of the injury and synergistic function of other structures in the foot, delayed presentation is common. Whilst pain was

\section{REFERENCES}

1. Coghlan BA, Clarke NM. Traumatic rupture of the flexor hallucis longus tendon in a marathon runner. Am J Sports Med 1993; 21(4):617-618.

2. Floyd DW, Heckman JD, Rockwood CA, Jr. Tendon lacerations in the foot. Foot ankle 1983; 4(1):8-14.

3. Frenette JP, Jackson DW. Lacerations of the flexor hallucis longus in the young athlete. J Bone Joint Surg Am 1977; 59(5):673-676

4. Goldmann JP, Bruggemann GP. The potential of human toe flexor muscles to produce force. J anat 2012; 221(2):187-194.

5. Grispigni C, De Ponti A, Danasini P, Sarto L. Closed subcutaneous rupture of the flexor hallucis longus tendon. Case report a common indication for surgical intervention, the time period for resolution of pain after the acute rupture is not well known. Pain, as an indication for surgery is a debatable notion, given pain may resolve with non-operative management due to its natural history alone.

It is unclear from the current body of literature if surgical management of this injury significantly improves patient outcomes. Further to this, operative management places patients at risk of surgical site infections and venous thromboembolism associated with immobilisation. Given that closed ruptures of the flexor hallucis longus tendon are often degenerative or attritional by their nature, they are unlikely to achieve normal tendon function despite surgical repair.

Our recommendation is for the initial non-operative treatment of closed flexor hallucis longus tendon ruptures given the potential for acceptable functional outcomes, and to avoid the potential complications associated with operative repair. Delayed surgery for persistent pain after a non-operative period is likely to yield similar results to a tenodesis performed acutely and acceptable salvage options exist for secondary deformities that may theoretically develop from the injury. In the elite athlete, the current body of literature is unclear on whether functional limitations will be encountered if surgical intervention is not undertaken.

The strengths of this review lie in the reproducible and scientific design. Further case reports detailing the outcomes of patients treated non-operatively are needed to help guide clinical decision making. Improved reporting of both clinical and functional outcomes scores is needed to better determine the long-term prognosis of this injury.

\section{Conflict of interest}

No author was paid or sponsored by any private company for the publication. The study authors have no conflict of interest to declare.

and review of the literature. Journal of Orthopaedics and Traumatology 2000; 1(2):107-110.

6. Holt KW, Cross MJ. Isolated rupture of the flexor hallucis longus tendon. A case report. Am J Sports Med 1990;18(6):645 646.

7. Inokuchi S, Usami N. Closed complete rupture of the flexor hallucis longus tendon at the groove of the talus. Foot ankle int 1997; 18(1):47-49.

8. Van Jonbergen JPW, Faber FWM, Treurniet FEE. Non-traumatic isolated rupture of the flexor hallucis longus tendon related to an os trigonum: a case report. Foot Ankle Surg 2001; 7(2):109-111.

9. Jacob HA. Forces acting in the forefoot during normal gait-an estimate. Clin Biomech (Bristol, Avon) 2001; 16(9):783-792. 
10. Noda D, Yoshimura I, Kanazawa K, Hagio T, Naito M. Subcutaneous rupture of the flexor hallucis longus tendon: a case report. Journal Foot Ankle Surg 2012; 51(2):234-236.

11. Rasmussen RB, Thyssen EP. Rupture of the flexor hallucis longus tendon: case report. Foot Ankle 1990; 10(5):288-289.

12. Romash MM. Closed rupture of the flexor hallucis longus tendon in a long distance runner: report of a case and review of the literature. Foot Ankle Int 1994; 15(8):433-436.
13. Thompson FM, Snow SW, Hershon SJ. Spontaneous atraumatic rupture of the flexor hallucis longus tendon under the sustentaculum tali: case report, review of the literature, and treatment options. Foot Ankle Int 1993; 14(7):414-417.

14. Wei SY, Kneeland JB, Okereke E. Complete atraumatic rupture of the flexor hallucis longus tendon: a case report and review of the literature. Foot Ankle Int 1998; 19(7):472-474. 